Erratum: "Azide-water intermolecular coupling measured by two-color two-dimensional infrared spectroscopy" [J. Chem. Phys. 136, 224503 (2012)]

\author{
Borek, Joanna ; Perakis, Fivos ; Kläsi, Felix ; Garrett-Roe, Sean ; Hamm, Peter
}

DOI: https://doi.org/10.1063/1.4739535

Posted at the Zurich Open Repository and Archive, University of Zurich ZORA URL: https://doi.org/10.5167/uzh-73360

Journal Article

Accepted Version

Originally published at:

Borek, Joanna; Perakis, Fivos; Kläsi, Felix; Garrett-Roe, Sean; Hamm, Peter (2012). Erratum: "Azidewater intermolecular coupling measured by two-color two-dimensional infrared spectroscopy" [J. Chem. Phys. 136, 224503 (2012)]. Journal of Chemical Physics, 137(6):069902.

DOI: https://doi.org/10.1063/1.4739535 


\title{
Erratum: Azide-water intermolecular coupling measured by two-color two-dimensional infrared spectroscopy
}

\author{
Joanna Borek ${ }^{1}$, Fivos Perakis ${ }^{1}$, Felix Kläsi ${ }^{1}$, Sean Garrett-Roe ${ }^{2}$, Peter Hamm ${ }^{1}$ \\ ${ }^{1}$ Physikalisch-Chemisches Institut, Universität Zürich, \\ Winterthurerstrasse 190, CH-8057 Zürich, Switzerland and \\ ${ }^{2}$ Department of Chemistry, University of Pittsburgh, \\ Chevron Science Center, 219 Parkman Avenue, Pittsburgh, PA 15260*
}

(Dated: July 20, 2012)

*Electronic address: phamm@pci.uzh.ch 
After publication of Ref. [1], it has been brought to our attention that Hochstrasser and coworkers have studied essentially the same molecular system (i.e., $\mathrm{N}_{3}^{-}$in $\mathrm{H}_{2} \mathrm{O}$ instead of $\mathrm{D}_{2} \mathrm{O}$ ) by two-color 2D IR spectroscopy before us [2]. A cross peak is also observed, which less likely is due to population transfer because of the even larger energy gap from the $\mathrm{N}_{3}^{-}$asymmetric stretch vibration to the $\mathrm{H}_{2} \mathrm{O}$ band. We had based our conclusion, that population transfer is the dominant coupling mechanism, mostly on the large frequency separation of the 0-1 and the 1-2 transition in the 2D IR spectra, which reflects the large anharmonicity of the OD vibrator itself [1]. The 1-2 transition is not shown in Ref. [2], so we cannot decide whether an alternative coupling mechanism might be responsible for the cross-peak between $\mathrm{N}_{3}^{-}$in $\mathrm{H}_{2} \mathrm{O}$. Nonetheless, Ref. [2] found a tilt in the cross-peak, evidencing a correlation in the vibrational frequencies the of $\mathrm{N}_{3}^{-}$and the $\mathrm{H}_{2} \mathrm{O}$ vibrations, which is another consequence of the coupling to azide-bound water.

[1] J. Borek, F. Perakis, F. Kläsi, S. Garrett-Roe, and P. Hamm, J. Chem. Phys. 136, 224503 (2012).

[2] C.-H. Kuo, D. Y. Vorobyev, J. Chen, and R. M. Hochstrasser, J. Phys. Chem. B 111, 14028 (2007). 